\title{
A Narrative Review on Factors Shaping the Vaginal Microbiome: Role of Health Behaviors, Clinical Treatments, and Social Factors
}

\author{
Emily Wissel ${ }^{1}$, Alexis Dunn ${ }^{1}$, and Anne Dunlop ${ }^{1}$ \\ ${ }^{1}$ Emory University
}

October 5, 2020

\begin{abstract}
It is not well understood why some healthy vaginal microbiomes are dominated by Lactobacillus and some are not. This review outlines factors which impact the vaginal microbiome and may explain this phenomenon. Specifically, hygiene practices, diet, sexual partners and practices, gender affirming treatments, stress, and social determinants are discussed. The goal of this review is to discuss key endogenous and exogenous factors that clinical experts and research scientists should consider when evaluating the vaginal microbiome in health and disease.
\end{abstract}

\section{Tweetable Abstract}

We review the many factors that influence the vaginal microbiome and reproductive health.

\section{Introduction}

The human microbiome is defined as all the microorganisms whose activity forms ecological niches on and inside the human body, and which sustains a dynamic and interactive relationship with their human host, becoming crucial for their functioning and health ${ }^{1}$. The human microbiome is typically evaluated by body site, with the gut microbiome being the most studied. There has been interest in exploring the role of the vaginal microbiome on human health. The vaginal microbiome has been linked with reproductive health outcomes, including risk for sexually transmitted infections and adverse birth outcomes ${ }^{2,3}$.

Much of the research on the vaginal microbiome is observational and focuses on the absence or presence of bacteria within one genus-Lactobacillus. The protective effect ofLactobacillus is largely attributed to its function of maintaining an acidic environment ${ }^{4,5}$. While Lactobacillus dominates the vaginal microbiome of most healthy individuals, there is a significant portion of healthy people whose vaginal microbiome is not dominated byLactobacillus, especially among Black and Hispanic individuals ${ }^{6}$.

The goal of this review is to discuss key endogenous and exogenous factors that clinical experts and research scientists should consider when evaluating the vaginal microbiome and its influence on health and disease. First, we will briefly overview the emergence of vaginal microbiome research as it is currently understood, and highlight some of the potential shortcomings and gaps in the science. Then, we will outline factors which are known to impact the vaginal microbiome and health outcomes which are important to consider in vaginal microbiome research, such as hygiene practices, diet, and stress. Finally, we will discuss future implications for clinical practice and research with a focus on how to move forward in this field and overcome the barriers discussed. 


\section{Early Vaginal Microbiome Research}

The vaginal microbiome is simpler than the microbiome of other body sites-a few species tend to dominate the vaginal microbiome, and all vaginal microbiomes can be categorized by a few enterotypes, or community profile. As such, there is a relatively uniform framework for characterizing the vaginal microbial community. Community state types (CSTs) were originally introduced in 2011 as a way of categorizing the composition of the vaginal microbiome ${ }^{5}$. The prevailing literature finds that there are five principal CSTs-four are marked by the dominance of Lactobacillus species and one is marked by the absence of this dominant member. This fifth CST, dubbed the "Diverse CST," consists of a lower prevalence ofLactobacillus along with a greater prevalence and number of other anaerobic microbes. The original analysis introducing CSTs noted that healthy women of different races and ethnicities exhibited different proportions of the five CSTs, but that, importantly, all CSTs were common in healthy women across all racial and ethnic groups.

Later literature further simplified characterization of the vaginal microbiome into a narrower concept Lactobacillus dominated communities versus diverse ones ${ }^{7}$. The presence of Lactobacillus tends to correlate with lower rates of sexually transmitted infections $(\mathrm{STI})^{3}$, lower rates of pregnancy complications ${ }^{8}$, and lower diagnosed cases of Bacterial Vaginosis $(\mathrm{BV})^{9}$. The plausible biological mechanism by which Lactobacillus exerts its protective effect is through the digestion of glycogen in the vaginal lining into lactic acid, creating a highly acidic vaginal environment. This acidic environment is hostile to the growth and proliferation of many pathogens that cause STIs and BV associated bacteria (BVAB). The proposed mechanism is difficult to experimentally test as even closely related animal models are physiologically different from humans ${ }^{10}$, and it can be unethical to experimentally test this in humans. As such, studies on the human vaginal microbiome are almost entirely observational.

Observational studies of the human microbiome often fail to account for many clinical and lifestyle factors, such as comorbid conditions, birth control method ${ }^{11}$, and recent sexual contact ${ }^{12}$, that have the potential to moderate the relationships observed between the vaginal microbiome and reproductive health risks. For example, it is largely unknown how comorbid conditions impact the vaginal microbiome despite their impact on the gut microbiome being known ${ }^{13-16}$. Further, sexual practices, most recent sexual contact, and birth control are not always accounted for despite being known to impact the vaginal microbiome ${ }^{3,11,17,18}$. When CSTs were introduced, it was noted that Black and Hispanic women were more likely than women of other ethnicities to fall into the Diverse CST $^{5}$. The women in this study were healthy with no reported vaginal symptoms. As such, the authors cautioned against assuming that the absence ofLactobacillus indicated an unhealthy state.

\section{Describing the "Healthy" Vaginal Microbiome}

Research implicating the presence of Lactobacillus as healthy stems from previous studies that have shown that those who haveLactobacillus dominated vaginal communities tend to have better health outcomes ${ }^{7,19}$. Recent research has challenged this view, though. While women with BV tend to have a higher vaginal $\mathrm{pH}$, a recent review of the literature found that no specific taxa, including Lactobacillus, was associated with vaginal $\mathrm{pH}^{10}$. In fact, it was documented early on that some people withLactobacillus dominated vaginal communities have a high vaginal $\mathrm{pH}^{5}$. Despite this evidence, much of the research focus has been on describing the role of Lactobacillus at the expense of holistically understanding the vaginal microbiome. As such, much of the research discussed here will outline how Lactobacillus is associated with health outcomes.

\section{The Vaginal Microbiome and Pregnancy Outcomes}

There are predictable and necessary immunologic, metabolic, and hormonal changes that allow a pregnant individual to provide nutrients and space for the developing fetus without mounting an immune response against $\mathrm{it}^{8}$. During a normal, healthy pregnancy, the microbiome becomes less diverse overall ${ }^{20}$. There is limited understanding of what changes constitute normal, healthy changes or changes which lead to 
pregnancy complications. It is known that pregnant individuals are more susceptible to UTIs, BV flare ups, and Candida infections during pregnancy ${ }^{21}$, and the changes in vaginal microbiome during pregnancy could play a role in this increased susceptibility. A vaginal microbiome that lacksLactobacillus is associated with increased risk for preterm birth $^{2,22,23}$, a leading cause of infant mortality in the United States ${ }^{24}$. However, it is not clear that the microbiome is a stronger predictor than other known risk factors, such as racism and stress $^{22}$. For a more thorough review of the vaginal microbiome in pregnancy outcomes, please see Edwards et al. ${ }^{8}$.

\section{Sexually Transmitted Infections}

The WHO estimated that 1 million new cases of STIs are acquired every day worldwide ${ }^{25}$. It is known that the vaginal microbiome is more diverse when certain STIs are present, such as chlamydia, HIV, and HPV 26-29, a trend that is true across race and ethnicity. It appears that STIs correlate with metabolic differences in the vagina of healthy versus STI communities, namely decreases in lactate, which is produced byLactobacillus , in the STI communities ${ }^{29}$, though this isn't always true for BV $^{30}$. Recent studies exploring Lactobacillus dominance identified an association between STIs and lower abundance of Lactobacillus in people of color ${ }^{31}$. Historically higher rates of STIs have been reported among minority communities, though this is due to a multitude of structural and behavioral factors ${ }^{32}$. It should be noted that the healthy reference group in STI-vaginal microbiome studies is often majority white (or race unreported). This means the reference group is significantly more likely to have aLactobacillus dominated community instead of the diverse community. It is currently unexplored how the healthy, diverse microbiome differs from the diverse community when STIs are present, except for documenting the presence of pathogens.

\section{Bacterial Vaginosis}

Bacterial Vaginosis (BV) is a complex clinical condition which is associated with symptoms of odor, discharge, and itching or pain in or around the vagina. While it is the most common vaginal condition in women aged 14-49, there may not be any symptoms present ${ }^{33}$. BV is treated with antibiotics, but it often returns after treatment.Lactobacillus crispatus is capable of inhibiting BV associated bacteria (BVAB) growth in vivo $^{34}$, while other Lactobacillus species appear to inhibit BVAB less effectively ${ }^{30}$. This indicates that those with Lactobacillus dominated communities have lower risk for BV than those with a diverse community. However, Black and Hispanic individuals are more likely to have BVAB present in their vaginal communities regardless of BV symptoms and diagnosis ${ }^{5,35,36}$. It is unclear how the healthy, diverse vaginal community impacts BVAB populations or risk for subsequent BV diagnosis.

\section{Factors Influencing the Vaginal Microbiome}

Other exogenous factors influence vaginal health and should be examined as they may play a significant role in influencing reproductive health outcomes and themselves may be associated with microbiome composition. In the United States, differences in health outcomes for groups defined by race/ethnicity are oftentimes confounded by inter-group differences in socioeconomic status, social determinants of health, and health behaviors linked to social determinants of health. The following sections will explore how vaginal hygiene practices, diet, sexual partners and practices, gender affirming treatments, stress, and social determinants impact the vaginal microbiome.

\section{Douching and Hygiene Practices}

The vagina is colloquially referred to as a "self-cleaning oven" because of its ability to maintain its cleanliness and health independent of the use of soaps or human-made cleansers. Despite this, the feminine hygiene market is a $\$ 1.1$ billion dollar industry as of 2018 and is expected to continue to grow ${ }^{37}$. Vaginal hygiene products include washes, wipes, moisturizers and creams, and other products. Researchers must be careful to use language that includes the diverse range of products people could be using, as asking about douching 
practices alone will not capture the full range of vaginal hygiene products known to impact the vaginal microbiome.

The use of vaginal cleansing products can have detrimental effects on vaginal health through several mechanisms. Soap is basic; the use of intravaginal vaginal cleansing products can disrupt the microbial community and prompt changes in the composition of the vaginal environment that can contribute to the development of disease ${ }^{38,39}$. Additionally, douching is capable of inhibiting the growth of Lactobacillus in vitro ${ }^{39}$ and changing the vaginal microbiome of women undergoing STI treatment ${ }^{40}$. One study found that of 1435 participants in Canada, 95\% reporting using at least one vaginal hygiene product. Participants who used any vaginal product had nearly three times higher odds of an adverse health condition such as reported history of BV, yeast infection, UTI, or STI ${ }^{41}$.

\section{Diet}

The human diet independent of probiotic consumption appears to impact the vaginal community. A study comparing the vaginal microbiomes of seven different primate species recently found that Lactobacillus dominated vaginal communities are a uniquely human phenomenon ${ }^{10}$. This is driven by the increased starch in human diets, which leads to increased glycogen deposition in the vaginal wall. As Lactobacillus breaks down glycogen for nutrients, the human vaginal environment became an excellent host for Lactobacilli species. It remains unclear if a-amylase is always required for Lactobacillus to break down glycogen ${ }^{10,42}$, and what level of starch consumption must be maintained for Lactobacillus to be viable in the vagina.

Studies examined the impact of probiotics in the form of yogurt and capsulated freeze dried bacteria on vaginal symptoms. More thorough reviews are provided elsewhere ${ }^{43-45}$, though an overview is provided here. While oral probiotic administration has been found to have a beneficial effect on vaginal symptoms and some pregnancy outcomes ${ }^{46-48}$, a vaginally administered probiotic was found to have no clinical effect ${ }^{49}$. A clinical trial investigating the effects of probiotics on preterm birth found that, while the probiotic did not reduce incidence of preterm birth, it did shift the composition of the vaginal microbiome towards an environment that is associated with lower inflammation and pathogen abundance ${ }^{50}$. A prospective cohort study found that women who ate milk-based probiotics containing Lactobacillus had lower rates of preterm birth and preeclampsia ${ }^{51}$. Despite these findings, a recent meta analysis did not find an effect of probiotics on preterm birth ${ }^{48}$. Further research needs to determine the mechanisms at play and whether probiotics are truly beneficial for vaginal health.

There is also evidence that micronutrients impact the vaginal microbiome and vaginal health. Increased dietary fat is associated with increased risk for BV, while increased intake of folate, vitamin A, and calcium was associated with decreased risk for $\mathrm{BV}^{52}$. A study of the fecal microbiome of lactating women found that micronutrient intake was associated with the relative abundance of specific, individual taxa ${ }^{53}$. Only the relative abundance of the phylum Firmicutes increased as more nutrient rich food was consumed. This implies that any dietary interventions will need to tailor the intervention to the specific health condition or taxa that is targeted. Taken together, these findings may be especially important for understanding the dynamics of the vaginal microbiome for patients who don't have access to or don't consume nutrient rich food.

\section{Sexual Partners and Practices}

Sexual partners impact the vaginal microbiome as there is direct contact between genitals and transfer of microbiota and fluids. Individuals with more sexual partners are consistently found to have a more diverse vaginal microbiome ${ }^{17,18}$. This is thought to be due to exposure to many microbes, as each sexual partner can carry different microbes and the disturbance of the vaginal microbiome as a result of fluid exchange between partners (whether that be saliva, semen, or vaginal fluid). Having more female sexual partners is associated with higher risk for exposure to pathogenic microbes, as female partners are more likely to carry BVAB, Group B Streptococcus, and other microbes thought to be detrimental to vaginal health ${ }^{54}$. It is 
thought that increased vaginal microbiome diversity, whether from the number or sex of sexual partners, is overall negative for vaginal health. However, this primarily rises out of the concept that diversity is present in unhealthy vaginal communities when Lactobacillus is in low abundance or absent. It is unclear whether diversity alone is a risk factor for poor vaginal health.

Sexual practices also have been shown to impact the vaginal microbiome. Increased male condom use is found to be associated with decreased risk for BV, likely due to exposure prevention ${ }^{11,28,55}$. Similarly, male circumcision is associated with decreased risk of BV for female sexual partners. Unprotected receptive oral sex appears to be associated with increased risk for BV, though this finding is not always replicated ${ }^{56}$. The effects of lubricant on the vaginal microbiome remains significantly understudied, but a recent observational study found that lubricant use in the day prior to vaginal sampling was associated with a higher Nuget score ${ }^{57}$. Birth control method and vaginal sex after anal sex are also associated with changes in the microbiome ${ }^{3,55}$, those these changes are not clearly defined yet.

\section{Gender Affirming Treatment}

It is important for health care providers to be prepared to care for a diverse population of patients, and for health science researchers to contextualize their research to the care provided for different populations. This includes groups utilizing hormone therapies and other gender affirming treatments. Gender affirming treatments, such as masculinizing hormone therapy or neovaginal surgery, can impact the vaginal microbiome in clinically important ways. Masculinizing hormone therapy was found to increase the diversity of the vaginal microbiome, and individuals undergoing this treatment were more likely to fall into the Diverse $\mathrm{CST}^{58}$. Longitudinal sampling will be required to identify whether masculinizing hormone therapy changes one's CST or if the baseline CST is the diverse group.

One gender affirming therapy for transgender women is neovaginal surgery, in which a vagina is constructed from existing penile and scrotal tissue and/or a colon graft. While research on the vaginal microbiome of those who undergo neovaginal surgery has been limited, new research indicates that understanding the neovaginal microbiome is clinically important. One study found that the neovaginal microbiome was highly diverse, composed largely of anaerobic bacteria, and triggered a host response similar to the response to $\mathrm{BV}^{59}$. Another study examining the neovaginal microbiome of five women with candida infection following neovaginal surgery found these women also had more BVAB in their vaginal microbiome ${ }^{60}$. Importantly, all five women in this study experienced several negative vaginal symptoms that were attributed to the microbiome and not just candida infection. In both studies, it was found that their vaginal microbiome was more similar to the skin and gut microbiome, possibly due to skin grafts during neovaginal surgery. There is high therapeutic potential in understanding how the vaginal microbiome contributes to symptoms following neovaginal surgery, but it is a multifaceted problem with many important considerations reviewed extensively in Mundluru \& Larson, $2018^{61}$.

\section{Stress}

Stress can capture many different experiences, from physical stress to psychosocial stress. Several mechanisms of stress-induced vaginal community disruption have been identified. First, stress-induced cortisol can bind to glucocorticoid receptors in the vaginal wall, which leads to an increase in proinflammatory cytokines, chemokines, and cause immunosuppression ${ }^{62}$. Further, stress-induced cortisol can inhibit the deposition of glycogen in the vaginal lining in a manner which restricts the Lactobacilli population ${ }^{63}$. It is possible that people who experience higher levels of stress have a vaginal microbiome that has adapted to rely on anaerobes which create an acidic environment without solely relying on Lactobacillus. Healthy Black and Hispanic individuals, who are less likely to harbor Lactobacillus in their vaginal microbiome, are more likely to experience high levels of stress and more likely than those of other ethnicities to have anaerobes in their vaginal community ${ }^{5,69}$. Taken together, this indicates that the vaginal microbiome adapts to not rely on Lactobacillus in the face of stress, as stress makes the vaginal environment less hospitable to Lactobacillus. 


\section{Broader Social Determinants}

Social determinants of health refer to the social and economic context in which someone is born and lives that influence their health ${ }^{64}$. This can manifest as access to affordable healthcare and housing, experiences of discrimination, and structural oppression ${ }^{65}$. Groups who experience greater disease burden tend to be impacted by social determinants of health. While there has not been research that has specifically examined how social determinants impact the vaginal microbiome, there has been work that indicates access to care and other social determinants impact the microbiome in a clinically relevant way ${ }^{66}$. A further review of the microbiome through the lens of social equity is available ${ }^{67}$ and is important for thinking about how structural barriers impact the health of one's microbiome. It is plausible that physiologic adaptations and changes in the microbiome may be driven by larger societal and systemic stressors such as racism, poverty, and education which influence health behaviors, decisions, and choices.

\section{Moving Forward}

Studies inconsistently account for factors known to influence the microbiome, such as hygiene practices, diet, and stress. Overlooking these factors may explain why it remains unclear that some individuals's vaginal communities are dominated by Lactobacillus and others lack it completely. By shifting the focus towards understanding the diverse CST and factors which shape the vaginal microbiome, research can move beyond associative understanding into relational understanding. Investigating this gap in knowledge is especially important for addressing health disparities and understanding the vaginal health of minority communities given the higher prevalence of diverse CSTs among of Hispanic and Black individuals. It is possible that accounting for factors which are known to impact the vaginal microbiome, research can better explain these gaps in knowledge.

The diverse CST must be understood for research on the vaginal microbiome to translate to improved patient care. New therapies, such as vaginal microbiota transfers, are being developed based on the concept that Lactobacillus dominated communities are the best fit for all individuals ${ }^{68}$. As there are differences in vaginal microbiomes, the community of best fit must be selected while taking into account the patient's healthy CST at baseline and potential moderating factors that may shift microbial community patterns (ex: stress, hygiene practices, etc). Given that the dominating paradigm focuses on Lactobacillus dominance, these new therapies may lead to the exclusion of people with the diverse CST and further health disparities.

While there are gaps in what is known and how research on the vaginal microbiome is conveyed, these gaps are mendable. The systematic evaluation of factors known to impact vaginal health and the vaginal microbiome may prove important to clinical scientists in the quest to develop effective therapies targeting vaginal conditions and subsequently improve patient care.

\section{Funding}

EFW is supported by the National Science Foundation Graduate Research Fellowship under Grant No. 1937971. ABD is supported by the National Center for Translational Sciences (NCATS) of the National Institutes of Health (NIH) under award number-UL1TR0002378.

\section{Disclosures of Interests}

The authors declare no competing interests.

\section{Contribution to Authorship}

EFW planned and drafted the initial manuscript. ALD and ABD provided critical feedback and revisions to the manuscript. All authors approve of the final version of this manuscript.

\section{References}


(1) Berg, G.; Rybakova, D.; Fischer, D.; Cernava, T.; Vergès, M.-C. C.; Charles, T.; Chen, X.; Cocolin, L.; Eversole, K.; Corral, G. H.; Kazou, M.; Kinkel, L.; Lange, L.; Lima, N.; Loy, A.; Macklin, J. A.; Maguin, E.; Mauchline, T.; McClure, R.; Mitter, B.; Ryan, M.; Sarand, I.; Smidt, H.; Schelkle, B.; Roume, H.; Kiran, G. S.; Selvin, J.; Souza, R. S. C. de; Overbeek, L. van; Singh, B. K.; Wagner, M.; Walsh, A.; Sessitsch, A.; Schloter, M. Microbiome Definition Re-Visited: Old Concepts and New Challenges.Microbiome 2020, 8 (1), 1-22. https://doi.org/10.1186/s40168-020-00875-0.

(2) Fettweis, J. M.; Serrano, M. G.; Brooks, J. P.; Edwards, D. J.; Girerd, P. H.; Parikh, H. I.; Huang, B.; Arodz, T. J.; Edupuganti, L.; Glascock, A. L.; Xu, J.; Jimenez, N. R.; Vivadelli, S. C.; Fong, S. S.; Sheth, N. U.; Jean, S.; Lee, V.; Bokhari, Y. A.; Lara, A. M.; Mistry, S. D.; Duckworth, R. A.; Bradley, S. P.; Koparde, V. N.; Orenda, X. V.; Milton, S. H.; Rozycki, S. K.; Matveyev, A. V.; Wright, M. L.; Huzurbazar, S. V.; Jackson, E. M.; Smirnova, E.; Korlach, J.; Tsai, Y.-C.; Dickinson, M. R.; Brooks, J. L.; Drake, J. I.; Chaffin, D. O.; Sexton, A. L.; Gravett, M. G.; Rubens, C. E.; Wijesooriya, N. R.; Hendricks-Muñoz, K. D.; Jefferson, K. K.; Strauss, J. F.; Buck, G. A. The Vaginal Microbiome and Preterm Birth. Nat. Med. 2019, 25 (6), 1012-1021. https://doi.org/10.1038/s41591-019-0450-2.

(3) Lewis, F. M. T.; Bernstein, K. T.; Aral, S. O. Vaginal Microbiome and Its Relationship to Behavior, Sexual Health, and Sexually Transmitted Diseases. Obstet. Gynecol. 2017, 129 (4), 643-654. https://doi.org/10.1097/AOG.0000000000001932.

(4) Kumamoto, Y.; Iwasaki, A. Unique Features of Antiviral Immune System of the Vaginal Mucosa. Curr. Opin. Immunol. 2012, 24 (4), 411-416. https://doi.org/10.1016/j.coi.2012.05.006.

(5) Ravel, J.; Gajer, P.; Abdo, Z.; Schneider, G. M.; Koenig, S. S. K.; McCulle, S. L.; Karlebach, S.; Gorle, R.; Russell, J.; Tacket, C. O.; Brotman, R. M.; Davis, C. C.; Ault, K.; Peralta, L.; Forney, L. J. Vaginal Microbiome of Reproductive-Age Women. Proc. Natl. Acad. Sci. 2011,108 (Supplement 1), 4680-4687. https://doi.org/10.1073/pnas.1002611107.

(6) Wells, J. S.; Chandler, R.; Dunn, A.; Brewster, G. The Vaginal Microbiome in U.S. Black Women: A Systematic Review. J. Womens Health 2020,29 (3), 362-375. https://doi.org/10.1089/jwh.2019.7717.

(7) Greenbaum, S.; Greenbaum, G.; Moran-Gilad, J.; Weintraub, A. Y. Ecological Dynamics of the Vaginal Microbiome in Relation to Health and Disease. Am. J. Obstet. Gynecol. 2019, 220 (4), 324-335. https://doi.org/10.1016/j.ajog.2018.11.1089.

(8) Edwards, S. M.; Cunningham, S. A.; Dunlop, A. L.; Corwin, E. J. The Maternal Gut Microbiome during Pregnancy. MCN. Am. J. Matern. Child Nurs.2017, 42 (6), 310-317. https://doi.org/10.1097/NMC.0000000000000372.

(9) Chen, H.-M.; Chang, T.-H.; Lin, F.-M.; Liang, C.; Chiu, C.-M.; Yang, T.-L.; Yang, T.; Huang, C.Y.; Cheng, Y.-N.; Chang, Y.-A.; Chang, P.-Y.; Weng, S.-L. Vaginal Microbiome Variances in Sample Groups Categorized by Clinical Criteria of Bacterial Vaginosis. BMC Genomics2018, 19 (10), 167-178. https://doi.org/10.1186/s12864-018-5284-7.

(10) Miller, E. A.; Beasley, D. E.; Dunn, R. R.; Archie, E. A. Lactobacilli Dominance and Vaginal PH: Why Is the Human Vaginal Microbiome Unique? Front. Microbiol. 2016, \%. https://doi.org/10.3389/fmicb.2016.01936.

(11) Brooks, J. P.; Edwards, D. J.; Blithe, D. L.; Fettweis, J. M.; Serrano, M. G.; Sheth, N. U.; Strauss, J. F.; Buck, G. A.; Jefferson, K. K. Effects of Combined Oral Contraceptives, Depot Medroxyprogesterone Acetate and the Levonorgestrel-Releasing Intrauterine System on the Vaginal Microbiome.Contraception 2017, 95 (4), 405-413. https://doi.org/10.1016/j.contraception.2016.11.006.

(12) Jespers, V.; van de Wijgert, J.; Cools, P.; Verhelst, R.; Verstraelen, H.; Delany-Moretlwe, S.; Mwaura, M.; Ndayisaba, G. F.; Mandaliya, K.; Menten, J.; Hardy, L.; Crucitti, T.; for the Vaginal Biomarkers Study Group. The Significance of Lactobacillus Crispatus and L. Vaginalis for Vaginal Health and the Negative 
Effect of Recent Sex: A Cross-Sectional Descriptive Study across Groups of African Women. BMC Infect. Dis. 2015, 15 (1), 115. https://doi.org/10.1186/s12879-015-0825-z.

(13) Tarantino, G. Gut Microbiome, Obesity-Related Comorbidities, and Low-Grade Chronic Inflammation. J. Clin. Endocrinol. Metab. 2014,99 (7), 2343-2346. https://doi.org/10.1210/jc.2014-2074.

(14) Johnson, C. Exploring the Gut Microbiome in Chronic Kidney Disease.2018.

(15) Evans, S. J.; Bassis, C. M.; Hein, R.; Assari, S.; Flowers, S. A.; Kelly, M. B.; Young, V. B.; Ellingrod, V. E.; McInnis, M. G. The Gut Microbiome Composition Associates with Bipolar Disorder and Illness Severity.J. Psychiatr. Res. 2017, 87, 23-29. https://doi.org/10.1016/j.jpsychires.2016.12.007.

(16) Pinto-Sanchez, M. I.; Ford, A. C.; Avila, C. A.; Verdu, E. F.; Collins, S. M.; Morgan, D.; Moayyedi, P.; Bercik, P. Anxiety and Depression Increase in a Stepwise Manner in Parallel With Multiple FGIDs and Symptom Severity and Frequency. Am. J. Gastroenterol. Springer Nat. 2015, 110 (7), 1038-1048. https://doi.org/10.1038/ajg.2015.128.

(17) Brotman, R. M. Vaginal Microbiome and Sexually Transmitted Infections: An Epidemiologic Perspective. J. Clin. Invest. 2011,121 (12), 4610-4617. https://doi.org/10.1172/JCI57172.

(18) Wessels, J. M.; Lajoie, J.; Vitali, D.; Omollo, K.; Kimani, J.; Oyugi, J.; Cheruiyot, J.; Kimani, M.; Mungai, J. N.; Akolo, M.; Stearns, J. C.; Surette, M. G.; Fowke, K. R.; Kaushic, C. Association of High-Risk Sexual Behaviour with Diversity of the Vaginal Microbiota and Abundance of Lactobacillus. PLOS ONE 2017, 12 (11), e0187612. https://doi.org/10.1371/journal.pone.0187612.

(19) Ma, B.; Forney, L. J.; Ravel, J. Vaginal Microbiome: Rethinking Health and Disease. Annu. Rev. Microbiol. 2012, 66 (1), 371-389. https://doi.org/10.1146/annurev-micro-092611-150157.

(20) Aagaard, K.; Riehle, K.; Ma, J.; Segata, N.; Mistretta, T.-A.; Coarfa, C.; Raza, S.; Rosenbaum, S.; Veyver, I. V. den; Milosavljevic, A.; Gevers, D.; Huttenhower, C.; Petrosino, J.; Versalovic, J. A Metagenomic Approach to Characterization of the Vaginal Microbiome Signature in Pregnancy.PLOS ONE 2012, 7 (6), e36466. https://doi.org/10.1371/journal.pone.0036466.

(21) Elkady, A.; Sinha, P.; Hassan, S. A. Z. Infections in Pregnancy: An Evidence-Based Approach; Cambridge University Press, 2019.

(22) Stout, M. J.; Zhou, Y.; Wylie, K. M.; Tarr, P. I.; Macones, G. A.; Tuuli, M. G. Early Pregnancy Vaginal Microbiome Trends and Preterm Birth. Am. J. Obstet. Gynecol. 2017, 217 (3), 356.e1-356.e18. https://doi.org/10.1016/j.ajog.2017.05.030.

(23) Petricevic, L.; Domig, K. J.; Nierscher, F. J.; Sandhofer, M. J.; Fidesser, M.; Krondorfer, I.; Husslein, P.; Kneifel, W.; Kiss, H. Characterisation of the Vaginal Lactobacillus Microbiota Associated with Preterm Delivery. Sci. Rep. 2014, 4 (1), 5136. https://doi.org/10.1038/srep05136.

(24) Ely, Danielle M. \& Driscoll, Anne K. Infant Mortality in the United States, 2017: Data From the Period Linked Birth/Infant Death File. Natl. Vital Stat. Rep. 2019, 68 (10), 1-19.

(25) JCI - Vaginal microbiome and sexually transmitted infections: an epidemiologic perspective https://www-jci-org.proxy.library.emory.edu/articles/view/57172 (accessed Aug 24, 2020).

(26) Cu-Uvin, S.; Hogan, J. W.; Caliendo, A. M.; Harwell, J.; Mayer, K. H.; Carpenter, C. C. J.; HIV Epidemiology Research Study. Association between Bacterial Vaginosis and Expression of Human Immunodeficiency Virus Type 1 RNA in the Female Genital Tract. Clin. Infect. Dis. 2001,33 (6), 894-896. https://doi.org/10.1086/322613.

(27) Shannon, B.; Yi, T. J.; Perusini, S.; Gajer, P.; Ma, B.; Humphrys, M. S.; Thomas-Pavanel, J.; Chieza, L.; Janakiram, P.; Saunders, M.; Tharao, W.; Huibner, S.; Shahabi, K.; Ravel, J.; Rebbapragada, A.; Kaul, R. Association of HPV Infection and Clearance with Cervicovaginal Immunology and the Vaginal Microbiota. Mucosal Immunol.2017, 10 (5), 1310-1319. https://doi.org/10.1038/mi.2016.129. 
(28) Fethers, K. A.; Fairley, C. K.; Hocking, J. S.; Gurrin, L. C.; Bradshaw, C. S. Sexual Risk Factors and Bacterial Vaginosis: A Systematic Review and Meta-Analysis. Clin. Infect. Dis. 2008, 47 (11), 1426-1435. https://doi.org/10.1086/592974.

(29) Ceccarani, C.; Foschi, C.; Parolin, C.; D’Antuono, A.; Gaspari, V.; Consolandi, C.; Laghi, L.; Camboni, T.; Vitali, B.; Severgnini, M.; Marangoni, A. Diversity of Vaginal Microbiome and Metabolome during Genital Infections. Sci. Rep. 2019, 9 (1), 14095. https://doi.org/10.1038/s41598-019-50410-x.

(30) Abdelmaksoud, A. A.; Koparde, V. N.; Sheth, N. U.; Serrano, M. G.; Glascock, A. L.; Fettweis, J. M.; Strauss, J. F.; Buck, G. A.; Jefferson, K. K. Comparison of Lactobacillus Crispatus Isolates from Lactobacillus-Dominated Vaginal Microbiomes with Isolates from Microbiomes Containing Bacterial Vaginosis-Associated Bacteria.Microbiology 2016, 162 (Pt 3), 466-475. https://doi.org/10.1099/mic.0.000238.

(31) Bertini, M. Is Time for Thinking to Vaginal Microbiome to Prevent Sexually Transmitted Diseases? Int. J. Fam. Community Med. 2018,2 (1). https://doi.org/10.15406/ijfcm.2018.02.00038.

(32) Cipres, D.; Rodriguez, A.; Alvarez, J.; Stern, L.; Steinauer, J.; Seidman, D. Racial/Ethnic Differences in Young Women's Health-Promoting Strategies to Reduce Vulnerability to Sexually Transmitted Infections. J. Adolesc. Health 2017, 60 (5), 556-562. https://doi.org/10.1016/j.jadohealth.2016.11.024.

(33) Koumans, E. H.; Sternberg, M.; Bruce, C.; McQuillan, G.; Kendrick, J.; Sutton, M.; Markowitz, L. E. The Prevalence of Bacterial Vaginosis in the United States, 2001-2004; Associations With Symptoms, Sexual Behaviors, and Reproductive Health. Sex. Transm. Dis. 2007, 34(11), 864-869. https://doi.org/10.1097/OLQ.0b013e318074e565.

(34) Eade, C. R.; Diaz, C.; Wood, M. P.; Anastos, K.; Patterson, B. K.; Gupta, P.; Cole, A. L.; Cole, A. M. Identification and Characterization of Bacterial Vaginosis-Associated Pathogens Using a Comprehensive Cervical-Vaginal Epithelial Coculture Assay. PLOS ONE2012, 7 (11), e50106. https://doi.org/10.1371/journal.pone.0050106.

(35) Zhou, X.; Brown, C. J.; Abdo, Z.; Davis, C. C.; Hansmann, M. A.; Joyce, P.; Foster, J. A.; Forney, L. J. Differences in the Composition of Vaginal Microbial Communities Found in Healthy Caucasian and Black Women.ISME J. 2007, 1 (2), 121-133. https://doi.org/10.1038/ismej.2007.12.

(36) Fettweis, J. M.; Brooks, J. P.; Serrano, M. G.; Sheth, N. U.; Girerd, P. H.; Edwards, D. J.; Strauss, J. F.; Jefferson, K. K.; Buck, G. A. Differences in Vaginal Microbiome in African American Women versus Women of European Ancestry. Microbiology 2014, 160 (Pt 10), 2272-2282. https://doi.org/10.1099/mic.0.081034-0.

(37) Feminine Intimate Care Market Size | Global Industry Report, 2019-2025 https://www.grandviewresearch.com/industry-analysis/feminine-intimate-care-market (accessed Aug 24, 2020).

(38) van der Veer, C.; Bruisten, S. M.; van Houdt, R.; Matser, A. A.; Tachedjian, G.; van de Wijgert, J. H. H. M.; de Vries, H. J. C.; van der Helm, J. J. Effects of an Over-the-Counter Lactic-Acid Containing Intra-Vaginal Douching Product on the Vaginal Microbiota. BMC Microbiol.2019, 19 (1), 168. https://doi.org/10.1186/s12866-019-1545-0.

(39) Full article: To 'douche' or not to 'douche': hygiene habits may have detrimental effects on vaginal microbiota https://www-tandfonline-com.proxy.library.emory.edu/doi/full/10.1080/01443615.2017.1395398 (accessed Aug 24, 2020).

(40) Helm, J. J. V. der; Loeff, M. F. S. van der; Vries, E. de; Veer, C. van der; Grunberg, A. W.; Mans, D.; Vries, H. J. C. de. Vaginal Herb Use and Chlamydia Trachomatis Infection: CrossSectional Study among Women of Various Ethnic Groups in Suriname. BMJ Open 2019,9 (5), e025417. https://doi.org/10.1136/bmjopen-2018-025417. 
(41) Crann, S. E.; Cunningham, S.; Albert, A.; Money, D. M.; O’Doherty, K. C. Vaginal Health and Hygiene Practices and Product Use in Canada: A National Cross-Sectional Survey. BMC Womens Health 2018,18 (1), 52. https://doi.org/10.1186/s12905-018-0543-y.

(42) Tester, R.; Al-Ghazzewi, F. H. Intrinsic and Extrinsic Carbohydrates in the Vagina: A Short Review on Vaginal Glycogen. Int. J. Biol. Macromol. 2018, 112, 203-206. https://doi.org/10.1016/j.ijbiomac.2018.01.166.

(43) Dunlop, A. L.; Mulle, J. G.; Ferranti, E. P.; Edwards, S.; Dunn, A. B.; Corwin, E. J. The Maternal Microbiome and Pregnancy Outcomes That Impact Infant Health: A Review. Adv. Neonatal Care Off. J. Natl. Assoc. Neonatal Nurses 2015, 15 (6), 377-385. https://doi.org/10.1097/ANC.0000000000000218.

(44) van de Wijgert, J.; Verwijs, M. C. Lactobacilli-Containing Vaginal Probiotics to Cure or Prevent Bacterial or Fungal Vaginal Dysbiosis: A Systematic Review and Recommendations for Future Trial Designs. BJOG Int. J. Obstet. Gynaecol. 2020, 127 (2), 287-299. https://doi.org/10.1111/1471-0528.15870.

(45) Li, C.; Wang, T.; Li, Y.; Zhang, T.; Wang, Q.; He, J.; Wang, L.; Li, L.; Yang, N.; Fang, Y. Probiotics for the Treatment of Women with Bacterial Vaginosis: A Systematic Review and Meta-Analysis of Randomized Clinical Trials. Eur. J. Pharmacol. 2019, 864, 172660. https://doi.org/10.1016/j.ejphar.2019.172660.

(46) Macklaim, J. M.; Clemente, J. C.; Knight, R.; Gloor, G. B.; Reid, G. Changes in Vaginal Microbiota Following Antimicrobial and Probiotic Therapy.Microb. Ecol. Health Dis. 2015, 26 (1), 27799. https://doi.org/10.3402/mehd.v26.27799.

(47) Luoto, R.; Laitinen, K.; Nermes, M.; Isolauri, E. Impact of Maternal Probiotic-Supplemented Dietary Counselling on Pregnancy Outcome and Prenatal and Postnatal Growth: A Double-Blind, PlaceboControlled Study.Br. J. Nutr. 2010, 103 (12), 1792-1799. https://doi.org/10.1017/S0007114509993898.

(48) Jarde, A.; Lewis-Mikhael, A.-M.; Moayyedi, P.; Stearns, J. C.; Collins, S. M.; Beyene, J.; McDonald, S. D. Pregnancy Outcomes in Women Taking Probiotics or Prebiotics: A Systematic Review and MetaAnalysis.BMC Pregnancy Childbirth 2018, 18 (1), 14. https://doi.org/10.1186/s12884-017-1629-5.

(49) Bisanz, J. E.; Seney, S.; McMillan, A.; Vongsa, R.; Koenig, D.; Wong, L.; Dvoracek, B.; Gloor, G. B.; Sumarah, M.; Ford, B.; Herman, D.; Burton, J. P.; Reid, G. A Systems Biology Approach Investigating the Effect of Probiotics on the Vaginal Microbiome and Host Responses in a Double Blind, Placebo-Controlled Clinical Trial of Post-Menopausal Women.PLOS ONE 2014, 9 (8), e104511. https://doi.org/10.1371/journal.pone.0104511.

(50) Vitali, B.; Cruciani, F.; Baldassarre, M. E.; Capursi, T.; Spisni, E.; Valerii, M. C.; Candela, M.; Turroni, S.; Brigidi, P. Dietary Supplementation with Probiotics during Late Pregnancy: Outcome on Vaginal Microbiota and Cytokine Secretion. BMC Microbiol. 2012, 12 (1), 236. https://doi.org/10.1186/1471-2180$12-236$.

(51) Brantsaeter, A. L.; Myhre, R.; Haugen, M.; Myking, S.; Sengpiel, V.; Magnus, P.; Jacobsson, B.; Meltzer, H. M. Intake of Probiotic Food and Risk of Preeclampsia in Primiparous Women. Am. J. Epidemiol.2011, 174 (7), 807-815. https://doi.org/10.1093/aje/kwr168.

(52) Thoma, M. E.; Klebanoff, M. A.; Rovner, A. J.; Nansel, T. R.; Neggers, Y.; Andrews, W. W.; Schwebke, J. R. Bacterial Vaginosis Is Associated with Variation in Dietary Indices. J. Nutr. 2011, 141(9), 1698-1704. https://doi.org/10.3945/jn.111.140541.

(53) Carrothers, J. M.; York, M. A.; Brooker, S. L.; Lackey, K. A.; Williams, J. E.; Shafii, B.; Price, W. J.; Settles, M. L.; McGuire, M. A.; McGuire, M. K. Fecal Microbial Community Structure Is Stable over Time and Related to Variation in Macronutrient and Micronutrient Intakes in Lactating Women. J. Nutr. 2015, 145 (10), 2379-2388. https://doi.org/10.3945/jn.115.211110.

(54) Bradshaw, C. S.; Walker, J.; Fairley, C. K.; Chen, M. Y.; Tabrizi, S. N.; Donovan, B.; Kaldor, J. M.; McNamee, K.; Urban, E.; Walker, S.; Currie, M.; Birden, H.; Bowden, F.; Garland, S.; 
Pirotta, M.; Gurrin, L.; Hocking, J. S. Prevalent and Incident Bacterial Vaginosis Are Associated with Sexual and Contraceptive Behaviours in Young Australian Women.PLOS ONE 2013, 8 (3), e57688. https://doi.org/10.1371/journal.pone.0057688.

(55) Noyes, N.; Cho, K.-C.; Ravel, J.; Forney, L. J.; Abdo, Z. Associations between Sexual Habits, Menstrual Hygiene Practices, Demographics and the Vaginal Microbiome as Revealed by Bayesian Network Analysis. PLOS ONE2018, 13 (1), e0191625. https://doi.org/10.1371/journal.pone.0191625.

(56) Forcey, D. S.; Vodstrcil, L. A.; Hocking, J. S.; Fairley, C. K.; Law, M.; McNair, R. P.; Bradshaw, C. S. Factors Associated with Bacterial Vaginosis among Women Who Have Sex with Women: A Systematic Review. PloS One2015, 10 (12), e0141905. https://doi.org/10.1371/journal.pone.0141905.

(57) Brotman, R. M.; Ghanem, K. G.; Klebanoff, M. A.; Taha, T. E.; Scharfstein, D. O.; Zenilman, J. M. The Effect of Vaginal Douching Cessation on Bacterial Vaginosis: A Pilot Study. Am. J. Obstet. Gynecol. 2008,198 (6), 628.e1-7. https://doi.org/10.1016/j.ajog.2007.11.043.

(58) Winston McPherson, G.; Long, T.; Salipante, S. J.; Rongitsch, J. A.; Hoffman, N. G.; Stephens, K.; Penewit, K.; Greene, D. N. The Vaginal Microbiome of Transgender Men. Clin. Chem. 2019, 65 (1), 199-207. https://doi.org/10.1373/clinchem.2018.293654.

(59) Birse, K. D.; Kratzer, K.; Zuend, C. F.; Mutch, S.; Noel-Romas, L.; Lamont, A.; Abou, M.; Jalil, E.; Veloso, V.; Grinsztejn, B.; Friedman, R. K.; Broliden, K.; Bradley, F.; Poliquin, V.; Li, F.; Yanavich, C.; Burgener, A.; Aldrovandi, G. The Neovaginal Microbiome of Transgender Women Post-Gender Reassignment Surgery. Microbiome 2020,8 (1), 61. https://doi.org/10.1186/s40168-020-00804-1.

(60) de Haseth, K. B.; Buncamper, M. E.; Ozer, M.; Elfering, L.; Smit, J. M.; Bouman, M.-B.; van der Sluis, W. B. Symptomatic Neovaginal Candidiasis in Transgender Women After Penile Inversion Vaginoplasty: A Clinical Case Series of Five Consecutive Patients. Transgender Health2018, 3 (1), 105-108. https://doi.org/10.1089/trgh.2017.0045.

(61) Mundluru, S. N.; Larson, A. R. Medical Dermatologic Conditions in Transgender Women. Int. J. Womens Dermatol. 2018, 4 (4), 212-215. https://doi.org/10.1016/j.ijwd.2018.08.008.

(62) Culhane, J. F.; Rauh, V. A.; Goldenberg, R. L. Stress, Bacterial Vaginosis, and the Role of Immune Processes. Curr. Infect. Dis. Rep.2006, 8 (6), 459-464. https://doi.org/10.1007/s11908-006-0020-x.

(63) Amabebe, E.; Anumba, D. O. C. Psychosocial Stress, Cortisol Levels, and Maintenance of Vaginal Health. Front. Endocrinol. 2018,9. https://doi.org/10.3389/fendo.2018.00568.

(64) WHO | About social determinants of health http://www.who.int/social_determinants/sdh_definition/en/ (accessed Aug 9, 2020).

(65) Social Determinants of Health | NCHHSTP | CDC https://www.cdc.gov/nchhstp/socialdeterminants/index.html (accessed Aug 24, 2020).

(66) Findley, K.; Williams, D. R.; Grice, E. A.; Bonham, V. L. Health Disparities and the Microbiome. Trends Microbiol. 2016, 24 (11), 847-850. https://doi.org/10.1016/j.tim.2016.08.001.

(67) Ishaq, S. L.; Rapp, M.; Byerly, R.; McClellan, L. S.; O’Boyle, M. R.; Nykanen, A.; Fuller, P. J.; Aas, C.; Stone, J. M.; Killpatrick, S.; Uptegrove, M. M.; Vischer, A.; Wolf, H.; Smallman, F.; Eymann, H.; Narode, S.; Stapleton, E.; Cioffi, C. C.; Tavalire, H. F. Framing the Discussion of Microorganisms as a Facet of Social Equity in Human Health. PLOS Biol. 2019, 17 (11), e3000536. https://doi.org/10.1371/journal.pbio.3000536.

(68) DeLong, K.; Bensouda, S.; Zulfiqar, F.; Zierden, H. C.; Hoang, T. M.; Abraham, A. G.; Coleman, J. S.; Cone, R. A.; Gravitt, P. E.; Hendrix, C. W.; Fuchs, E. J.; Gaydos, C. A.; Weld, E. D.; Ensign, L. M. Conceptual Design of a Universal Donor Screening Approach for Vaginal Microbiota Transplant. Front. Cell. Infect. Microbiol. 2019,9.https://doi.org/10.3389/fcimb.2019.00306. 
(69) Brown, Lauren L., Uchechi A. Mitchell, and Jennifer A. Ailshire. "Disentangling the stress process: Race/ethnic differences in the exposure and appraisal of chronic stressors among older adults." The Journals of Gerontology: Series B 75, no. 3 (2020): 650-660. 